\title{
Depresión postparto, los riesgos y su temprana detección
} Postpartum depression: Risks and early detection

La depresión postparto, también denominada depresión puerperal, es un problema frecuente en las madres durante el primer mes después del nacimiento, o a veces hasta un mayor tiempo. Los datos a nivel mundial señalan que su frecuencia oscila entre el $10 \%$ y el $20 \%$, aunque puede ser mayor y alcanzar el $26 \%$, que ocurren en madres adolescentes, solteras, y más especialmente, en las que tienen una baja situación social, pobreza, desnutrición y escasa educación. Esta situación nos está mostrando que una de cada cuatro madres padecen este problema, aunque es posible que no tengan un trastorno grave.

El Manual Diagnóstico y Estadístico de Trastornos Mentales en su quinta edición (DSM-V) señala que el trastorno psiquiátrico depresivo de mayor importancia, es cuando los síntomas ya se pueden observar durante el embarazo, mientras que las que tienen un menor riesgo presentan una depresión postparto, que suele aparecer en las primeras semanas después del nacimiento.

La repercusión de este trastorno con depresión afecta especialmente al bienestar de la madre, aunque también puede tener escasos cuidados a su hijo desde los primeros días del nacimiento, en especial cuando la madre no ha podido amamantarlo, o no tuvo el deseo. También es algo frecuente que no haya podido acercarse a su hijo hablándole, que es lo que habitualmente hacen las madres. En ocasiones, su trastorno puede afectar al padre del bebé, y a otros miembros de la familia, aunque es posible que sea poco frecuente.

Asimismo, se han identificado grupos de riesgo en las madres, en especial cuando los trastornos ocurren durante el embarazo donde se observa que tienen una mayor vulnerabilidad. No obstante, la que existe con bastante mayor frecuencia, aparece en el primer mes, aunque también puede extenderse hasta los primeros tres meses después del parto. En estos períodos, es imprescindible que los médicos ayuden a las madres, antes y después del nacimiento, que estará a cargo de obstetras y pediatras, ya que las madres suelen conocerlos bien y confían en que pueden ayudarlas. Para lograr eso, los médicos en la consulta deben ser sensibles y escuchar lo más posible a las madres, y de esa forma podrían detectar algunos síntomas de este trastorno. Cuando eso ocurre en las consultas posparto, ya sea con el obstetra o con el pediatra, será necesario que hagan una evaluación integral para que progresivamente puedan encontrar los dos síntomas más frecuentes, la depresión con un bajo estado de ánimo y la pérdida de interés en su bebé.

Las causas de la depresión posparto no están muy claras, pero los siguientes factores suelen asociarse con un mayor riesgo. Los trastornos que se pueden observar mayormente son: depresión en otro embarazo o en el postparto anterior, los síntomas que aparecen en la gestación actual, tristeza intensa, ansiedad, llanto frecuente, cambios de humor, irritabilidad, sensación de agobio, alteración del sueño, estrés por la ausencia del padre de su hijo durante el embarazo, ausencia de pareja luego del nacimiento y falta de apoyo de los familiares.

Los síntomas pueden ser similares a los de una depresión mayor, y también suelen incluir preocupaciones y temores acerca de ser madre. En esta situación, es adecuado decirles a las madres que es necesario que tengan un asesoramiento psicológico, que es lo que puede comenzar a mejorarlas en unas tres a cuatro semanas. Asimismo, cuando se observa que la depresión sigue persistiendo luego de los primeros meses, es común que los psiquiatras indiquen antidepresivos ya que pueden ser beneficiosos, y la mejoría aparece alrededor de los 30 días. También, puede ocurrir algo aún más grave, pero muy poco frecuente, denominado psicosis posparto o psicosis puerperal, que requiere un tratamiento psiquiátrico apenas se haya detectado. Asimismo, diversos estudios señalaron que el mayor riesgo ocurre cuando la depresión posparto se da en madres que tienen varios problemas pero principalmente, cuando la depresión ya estaba presente durante el embarazo, y no fue tratada.

También se ha observado que después del parto existe una rápida disminución del nivel de hormonas reproductivas, y probablemente eso puede contribuir a que ocurra la depresión en madres que son susceptibles. Es muy posible que los cambios hormonales aporten diversos factores que generan la depresión postparto.

Otros problemas relacionados con el embarazo, tal como un nacimiento prematuro (antes de las 34 semanas), o un bebé con algún 
defecto congénito, pueden ser la causa de la depresión. También ocurre este trastorno cuando la inseguridad tiene una relación con el embarazo actual, como que no fue planeado o que la madre consideró realizar un aborto.

Hay algunas madres que no tiene depresión, pero manifiestan un sentimiento de tristeza o melancolía en los primeros 3 a 5 días luego del nacimiento. En esas ocasiones, los profesionales de enfermería, obstetras y neonatólogos, pueden decirles a esas madres que no deben preocuparse mucho, porque estos sentimientos suelen ir desapareciendo antes de las dos semanas. Aun así, es absolutamente necesario citarlas unos días después del alta, y de ser posible, en cada semana hasta el primer mes.

Por lo tanto, es adecuado enseñar a todas las madres a reconocer los síntomas de la depresión posparto, y preguntarles acerca de la presencia de los mismos, antes y después del parto. Con estas acciones, es muy probable que se logren obtener los mejores resultados posibles a través de una identificación temprana, y tratar la depresión posparto desde las primeras semanas.

Con los trastornos que hemos visto, es necesario que se realice una pesquisa sistemática de los síntomas durante el embarazo, y en especial continuar durante las primeras semanas posparto para detectar la depresión, sobre todo en madres con factores de riesgo. Habitualmente, la pesquisa se realiza con la Escala de Edimburgo (Edinburgh Postnatal Depression Scale-EPDS-). Hay una versión escrita en español con los 10-elementos y es muy simple para realizarla, por lo cual puede efectuarse en todos los hospitales.
En el Hospital Italiano de Buenos Aires, se realiza desde hace unos 10 años y los pediatras que efectúan la Escala de Edimburgo detectan en las primeras semanas los trastornos que llevan a la depresión postparto, y apenas lo detectan, se comienza con el tratamiento adecuado.

Sin duda, es realmente necesario que en los hospitales de nuestro país se realice la pesquisa sistemática con la Escala de Edimburgo para poder detectar la depresión tempranamente.

José María Ceriani Cernadas

Editor

http: / / dx.doi.org/10.5546/ aap.2020.154

Texto completo en inglés:

http:/ / dx.doi.org/10.5546/ aap.2020.eng.154

Cómo citar: Ceriani Cernadas JM. Depresión postparto, los riesgos y su temprana detección. Arch Argent Pediatr 2020;118(3):154-155.

\section{REFERENCIAS}

- Patel M, Bailey RK, Jabeen S, Osiezagha K, et al. Postpartum Depression: A Review. J Health Care Poor Underserved. 2012; 23(2):534-42.

- Mendoza C,SaldiviaS. Actualización en depresión postparto: el desafío permanente de optimizar su detección y abordaje. Rev Med Chile. 2015; 143(7):887-94.

- Stewart DE, Vigod S. Postpartum depression. N Engl J Med. 2016; 375(22):2177-86.

- Moldenhauer JS. Postpartum depression. MSD Manual. 2018. [Acceso: 26 de febrero de 2020]. Disponibleen: https: / / www.msdmanuals.com/professional/gynecology-andobstetrics / postpartum-care-and-associated-disorders / postpartum-depression 